Buzz. Pharm. Sci., Assiut University

Vol, 9. Part 2, pp $144-156$

\title{
ON THE INTERACTION BETWEEN RIFAMPICIN AND MACROMOLECULES
}

\author{
1-POLYSORBATES
}

\author{
F.S. Hahib, S. Ismail, S. El-Shanawany and E.A. Fouad \\ Dept of Pharmaceutics, Faculty of Pharmacy, Assiut University \\ Assiut, Egypt.
}

\begin{abstract}
The permeation rates of rifampicin through a standard cellophane membrane were investigated in presence of different polysorbates. The surfactants were used in a concentration range of $0.2-0.6 \% \mathrm{w} / \mathrm{v}$. The data revealed that as the surfactant concentration was increased, the diffusion rates were found to be decreased. This was explained on the basis that as the surfactant concentration was increased, the partial voIume fraction was consequently. increased and a large amount of rifampicin was incorporated inside the micelzar core. These incorporated rifampicin molecules are not ready to permeate through the membrane. The tangmuir plots as well as spectrophotometric analysis indicate that a complex formed between rifampicin and the tested polysorbates. This complex is not ready, also, to penetrate through the membrane. It was found that the limiting adsorption capacities of surfactants were almost the same. This was explained on the basis that they are characterized by having the same number of oxyethylene units.
\end{abstract}




\section{INTRODUCT ION}

In pharmaceutical preparations, different surfactants have been employed so as to formulate either dispersed or solubilized systems ${ }^{1,2}$. Since non-ionic surfactants are less toxic to the biological systems they are particularly often used for formulation of such preparations ${ }^{3}$. However, it is well known that drug-surfactant interactions modify the rate of intestinal absorption of drugs ${ }^{4}$. rkeda and coworkers ${ }^{5}$ studied the miceliar interaction of tetracycline antibiotics at various pHs by dynamic dialysis

In last decades, considerable attention had been centered on the interaction of preservatives with non-ionic macromolecules . $^{6}$ The interaction of methyl and propyl esters of p-hydroxybenzoic acid with Tween 80 has been studied quantitatively by means of a dialysis method. The authors found that a relatively high degree of interaction had been observed, and the binding had been found to be a function of both the concentration of unbound preservative and Tween 80. The data obtained by Patel and Kostenbauder ${ }^{8}$ facilitate the calculation of the quantity of methyl or propyl paraben which must be added to the system containing a known concentration of Tween 80 so as to have the desired concentration of unbound preservative.

According to the theory of micellar formation, it is considered that drugs in surfactant solutions are partitioned between the "micellar phase" and the surrounding "aqueous phase". It was pointed out that the drug in the aqueous phase is medically active, while that associated within the micellar phase is acting as a reservoir ${ }^{11}$. Recently. Ismail et al. . $^{2}$ determined the partition coefficient of ethacrynic acid between the micelles of some non-ionic surfactants and the surrounding aqueous phases using the solubility technique. The partition coefficient of aspirin 
On the Interaction Between Rifampicin and Macromolecules 1-Polysorbates.

between the micelles of polysorbates and the aqueous phase was kinetically calculated and it was found that the partition coefficients were dependent on the type of polysorbate used. If drugs in the aqueous phase of surfactant solution are removed rapidly by some causes, it will be expected that the drug molecules in the micellar phase will be distributed to the aqueous phase when tough time or stirring is supplied.

From the pharmaceutical point of view, it is valuable to investigate the interaction between a drug and macromolecules. The estimation of the number of binding sites ( $n$ ) as well as the corresponding association constant (k) is a good guide for a knowledge of the nature of the active sites of macromolecules and the nature of the binding forces.

A variety of methods are often used for estimation of ( $n$ ) and (K) values. Such methods include equilibrium dialysis 14,15 , non-equilibrium partitioning ${ }^{16}$, ultrafiltration ${ }^{17,18}$, ultracentrifugation ${ }^{19}$, gel filtration ${ }^{20}$ and dynamic dialysis ${ }^{2}$.

Rifampicin, being an antibiotic, is often used in chemotherapy of tuberculosis. An attempt was carried out to improve its aqueous solubility by solubilization in aqueous solution of non-ionic surfactants ${ }^{1}$. This investigational work was done so as to study the diffusion rate of rifampicin when it was incorporated with polysorbates in concentration above their respective CMC's. Also the study is concerned with the estimation of the physical parameters associated with the interaction between rifampicin and polysorbates. 


\section{S. Ismail $\underline{\text { et }} \underline{\alpha} \underline{I}$.}

\section{EXPERIMENTAL}

\section{Materials:}

Rifampicin ${ }^{a}$, polysorbate 20,60 and $80^{b}$, and cellophane membrane ${ }^{c}$, Membrane Permeation Procedure:

The dialysis unit is composed of two compartments separated by a semipermeable cellophane membrane (30/32). A $5 \mathrm{ml}$ sample of rifampicin aqueous solution $(200 \mathrm{mcg} / \mathrm{ml})$, either alone or in the presence of surfactant, was pipetted into the inner compartment and $20 \mathrm{ml}$ distilled water was placed into the outer compartment. The inner compartment was immersed into the outer one in such a manner that the surface levels of the two solutions are the same. The upper part of the inner compartment was covered with a thinly perforated nylon membrane, so as to maintain the volume of the inner solution constant during the experimental study. The tested polysorbates were used without further purification, in a concentration range of $0.2-0.6 \% \mathrm{w} / \mathrm{v}$

The dialysis units were placed in a water bath shaker. The temperature was kept constant at $37^{\circ} \mathrm{C}$ and the rate of shaking was adjusted at 50 r.p.m. The amount of rifampicin diffused through the cellophane membrane was analyzed spectrophotometrically at $333 \mathrm{~nm}$ against a blank similarly treated. It should be noted that each expreiment was done in triplicate and the average amount of rifampicin difused at any specified time was calculated.

\section{RESULTS AND DISCUSSION}

In course of this investigational study, it should be noted that there was no discrepancy between the amount of rifa-mpicin found in solution at equilibrium and the initial amount

a - Supplied by El-Nile Pharmaceutical Co., Egypt.

b - Merk.

c-Fischer Sci. Co., London. 
On the Interaction Betwe Rifampicin and Macromolecules 1-Polysorbates.

added. This abservation indicates that the tendency of the cellophane membrane to adsorb the drug is negligible. The possibility of the tested polysorbates to be bound by the membrane was not investipated since it was assumed that any polysorbate bound by the semipermeable membrane would be negligible in comparison to the relatively high concentrations of polysorbate added to the system.

The permeation rates of rifampicin through the semipermeable membrane, in presence of different concentrations of polysorbates are graphicaliy presented in Figures 1-3. From these plots, it could be concluded that the diffusion of rifampicin through the membrane obeyed a first-ordex reaction. The diffusion rate constants were calculated and surveyed in Table 1 .

Table 1 : Diffusion Rate Constants $\left(\mathrm{hr}^{-1} \times 10^{2}\right)$ of Rifampicin Through a Standard Cellophane Membrane, in Presence of Different Polysorbate Concentrations .

\begin{tabular}{|c|c|c|c|c|}
\hline \multirow{2}{*}{ Surfactant } & \multicolumn{4}{|c|}{ Polysorbates Concentration. $\% \mathrm{w} / \mathrm{v}$} \\
\hline & 0 & 0.2 & 0.4 & 0.6 \\
\hline Polysorbate 20 & 4.19 & 4.33 & 2.69 & 2.72 \\
\hline Polysorbate 60 & 4.19 & 3.55 & 2.09 & 1.22 \\
\hline Polysorbate 80 & 4.19 & 3.84 & 2.85 & 2.22 \\
\hline
\end{tabular}

From this table, it could be observed that the tested polysorbates, when they were used in concentrations above their respective CMC's exhibited a marked retarding effect on the diffusion rate of the drug, being compared with the control. It was evident, that the drug molecules solubilized in the micellar phase are rapidly transferred into the aqueous phase, even if any stirring was not applied. Those drug molecules localized in the 
aqueous phase are actualiy ready to diffuse through the semipermeable membrane. The miceliar to aqueous transfer of drug molecules occurs instantaneously corresponding to the decrease in the drug concentration of the aqueous phase.

The Langmuir's plots were constructed for rifampicin-polysorbates systems so as to throw a beam of light on the mechanism through which the retarding effect of those polysorbates on the diffusion characteristics of rifampicin was observed. Figure 4 represents a typical plot for Langmuir isotherm in which a linearity was exhibited for the range of the drug concentration employed. The data were plotted in this manner to obtain the limiting binding capacity of each polysorbate used, at infinitely high rifampicin concentration. The Y-intercept is the reciprocal of the limiting quantity of rifampicin bound per one gram of polysorbate. These Langmuir graphs are of particular interest in the present study, since the existence of the Y-intercept suggests that complex formation is a factor in the binding of the rifampicin by the tested polysorbate.

The uv - absorption spectra of rifampicin aqueous solution (20 $\mathrm{mcg} / \mathrm{m} 1)$, either alone or in presnce of $0.6 \% \mathrm{w} / \mathrm{v}$ polysorbate 80 was carried out, Fig. 5. From this Figure it is clearly observed that a hypthachromic shift is present. This indicates that there is an interaction between rifampicin and polysorbate 80 . This ascertains what is shown by the Langmuir's plots, Fig. 4, in which an intercept of the Y-axis is present.

The Y-intercepts in Fiugre 4 indicate that the limiting binding capacities of the investigated polysorbates are about the same. This could be explained on the basis that polysorbates are characterized by having the same number of polyoxyethylene units are considered, herein, as the sites for interactions. 
On the Interaction Between Rifampicin and Macromolecules 1-Polysorbates.

They are, also, characterized by having different lipophilic portions. The significant difference between the diffusion rate of rifampicin, in presence of the tested polysorbates is probably attributed to the difierence in the distribution coefficient of drug between the miceliar and aqueous phases. This difference in the magnitude of the distribution coeffecient is, actually, due to the difference in the lipophilic moiety of each polysorbate.

The data obtained revealed that as the surfactant concentration was increased, the diffusion rate constant was found to be decreased, Table 1. The phenomenon is actually due to the fact that, as the surfactant concentration was increased, its volume fraction was, subsequently, increased resulting in an incorporation of a large amount of the drug inside the micellar core. It is well recognized that the solubilized drug molecules will not be ready to permeate through the membrane otherwise after being transferred from the miceliar into the aqueous phase. 
S. Ismail et al
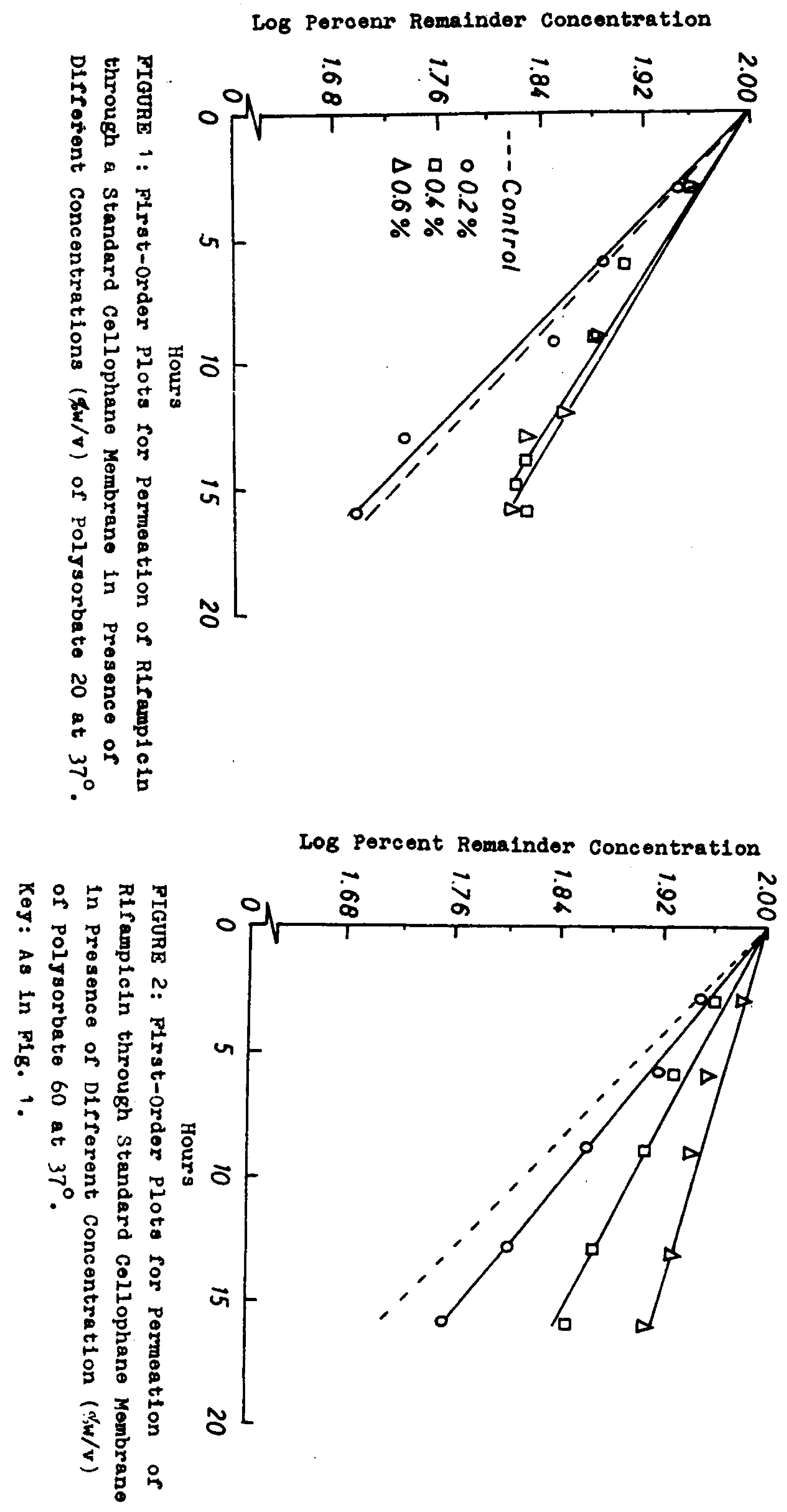


\section{2}

on the Interaction Between Rifampicin and Macromolecules 1-Polysorbates.

Log Percent Remainder Concentration
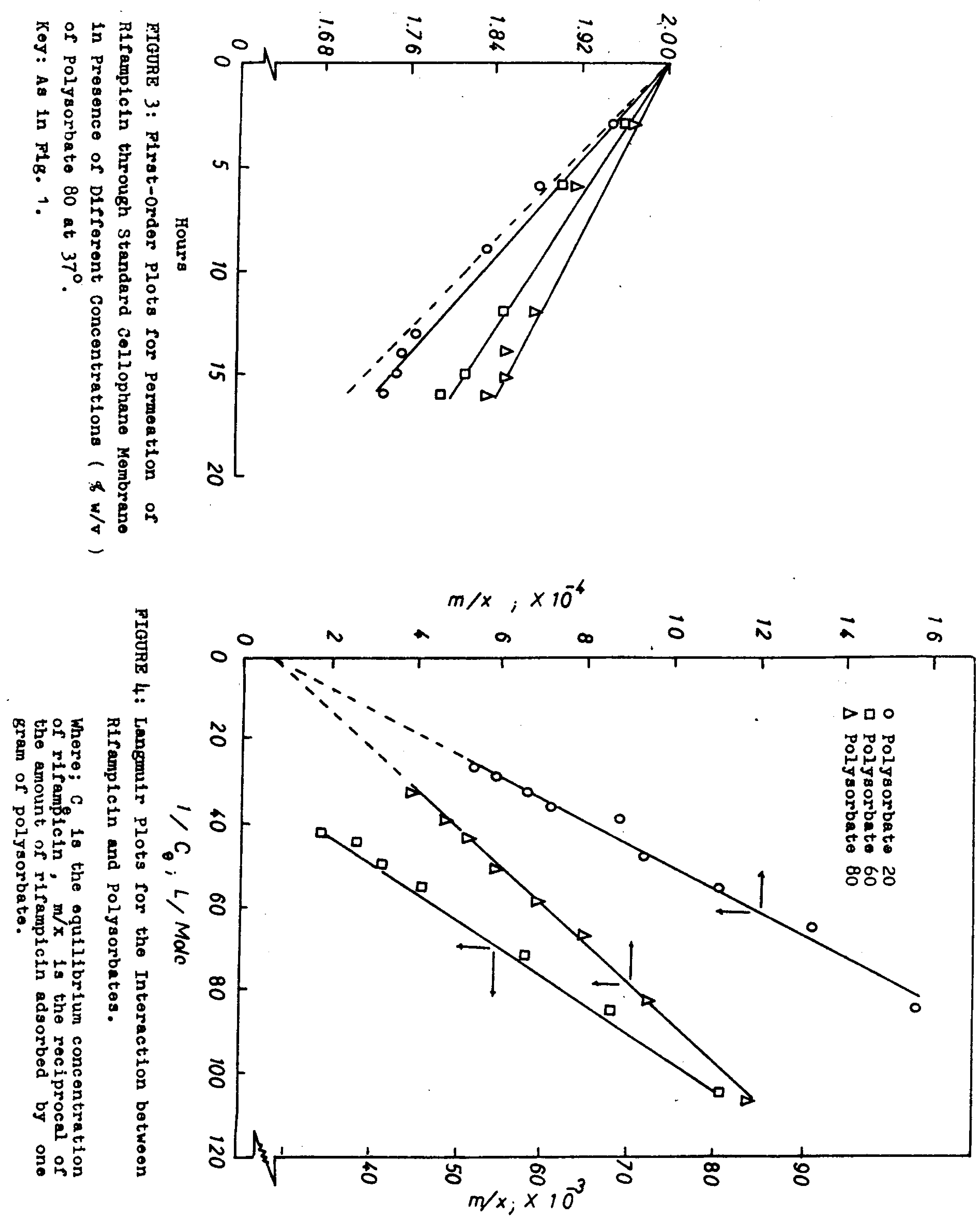
S. Ismail e $\underline{t} \underline{a} \underline{I}$

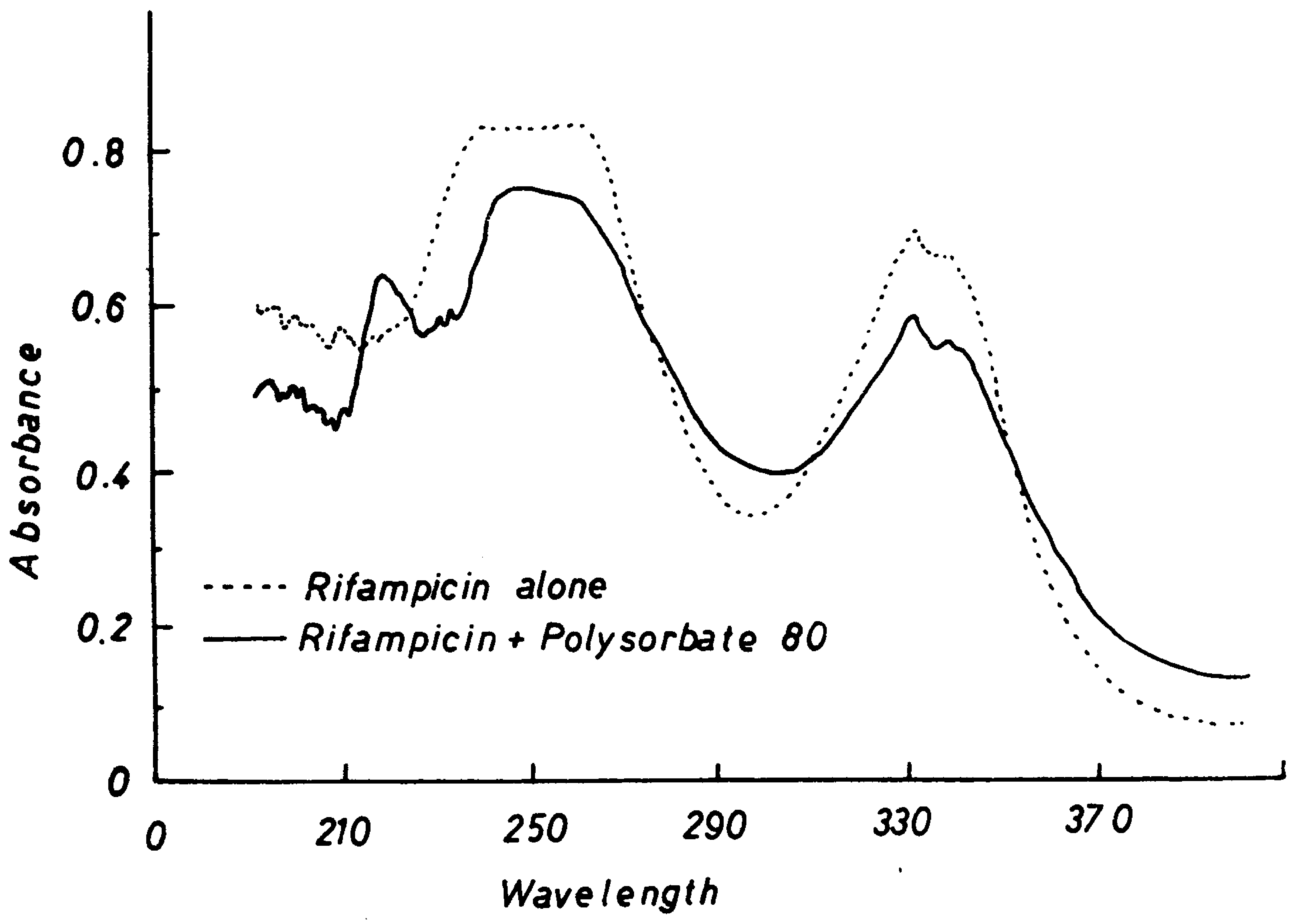

FIGURE 5: UV-Absorptiob Spectra of Rifampicin $(20 \mathrm{mcg} / \mathrm{ml})$ in Presence of Polysorbate $80(0.6 \% \mathrm{w} / \mathrm{v})$. 
On the Interaction Between Rifampicin and Macromolecules 1-Polysorbates.

\section{REFERENCES}

1) S.A. Ibrahim, A.A. Kassem, I.A. Attia and S. Ismaiz; BuZZ Pharm. Sci., Assiut Univ., 2, 1 (1979).

2) A.A. Ismail and M.A.F. Gadalza; Pharmazie, 38, 733 (1983).

3) B.A. Mulley, "Advances in Pharmaceutical Sciences", Academic press, London, 1964, p. 164.

4) M. Gibaldi and S. Feldman, J. Pharm. Sci., 59, 579, (1970).

5) K. Ikeda, H. Tomida and T. Yotsuyanagi, Chem. Pharm. BulZ. 25, 1067 (1977).

6) S.M. Blaug and S.S. Ahsan, J. Pharm. Sci., 50, 138 (1961).

7) Ibid, $\underline{50}, 441$ (1961).

8) N.K. PateZ and H.B. Kostenbauder, J. Am. Pharm. Assoc., 4?, 289 (1958).

9) N.K. Patel and N.E. Foss, J. Pharm. Sci., 53, 94, (1964).

10) Ibid, 5노 1495 (1965).

11) M.Matsumoto and M. Aoki, Chem. Pharm. Bulz., 10, 251(1962).

12) S. Ismail, F.S. Habib and M.A. Attia, Acta Pharm. Fenn.,.94 $\$ 63(1985)$.

13) S. Ismail and A.P. SimonezZi., BulZ. Pharm. Sci., Assiut Univ., 119 (1988).

14) J. Sato, Y. Sugiyama and M. Hanano, J. Pharm. Sci., 23, 519 $(1984)$.

15) D. Morin, R. Zini, S. Ledewyn, J.P. Colonna,

M. Crajka and J.P. Tizlement, Ibid, ?4, 727 (1985).

16) J.S. Robertson and B.W. Madsen, ibid, 63, 234 (1974).

17) J.B. Whitlam and K.F. Brown, Ibid, ?0, 146 (1981).

18) M.V. Calvo and A. Domingvez-Gil, Inter. J. Pharmaceutics, 12, $215(1983)$. 
19) Y. Matsusbita and I. Moriguchi, Chem . Pharm. Bulz., 33, 2948 (1985).

20) Y.T. Oester, S.K. Nagy, R.F. Mais, J. Becktel and J.F. Zaroslinski, J. Pharm. Sci., 65, 1673 (1976).

21) P.C. Farrelz, R.P. Popovich and A.L. Bobb, ibid, 60, 1471 (1971).

22) T. Higuchi, and J.L. Lach, J.Am. Pharm. Assoc., Sci., Ed., 53, $465(1954)$. 
تفـــاعل الريفـامبيســــيـن مع الـجزئيـات الكبيــرة

1

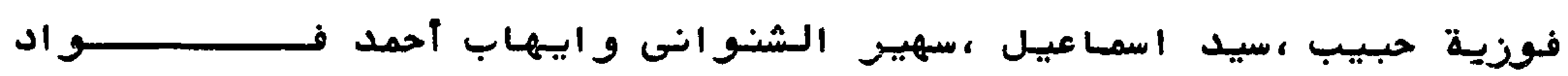

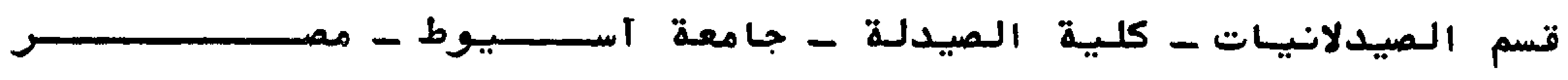

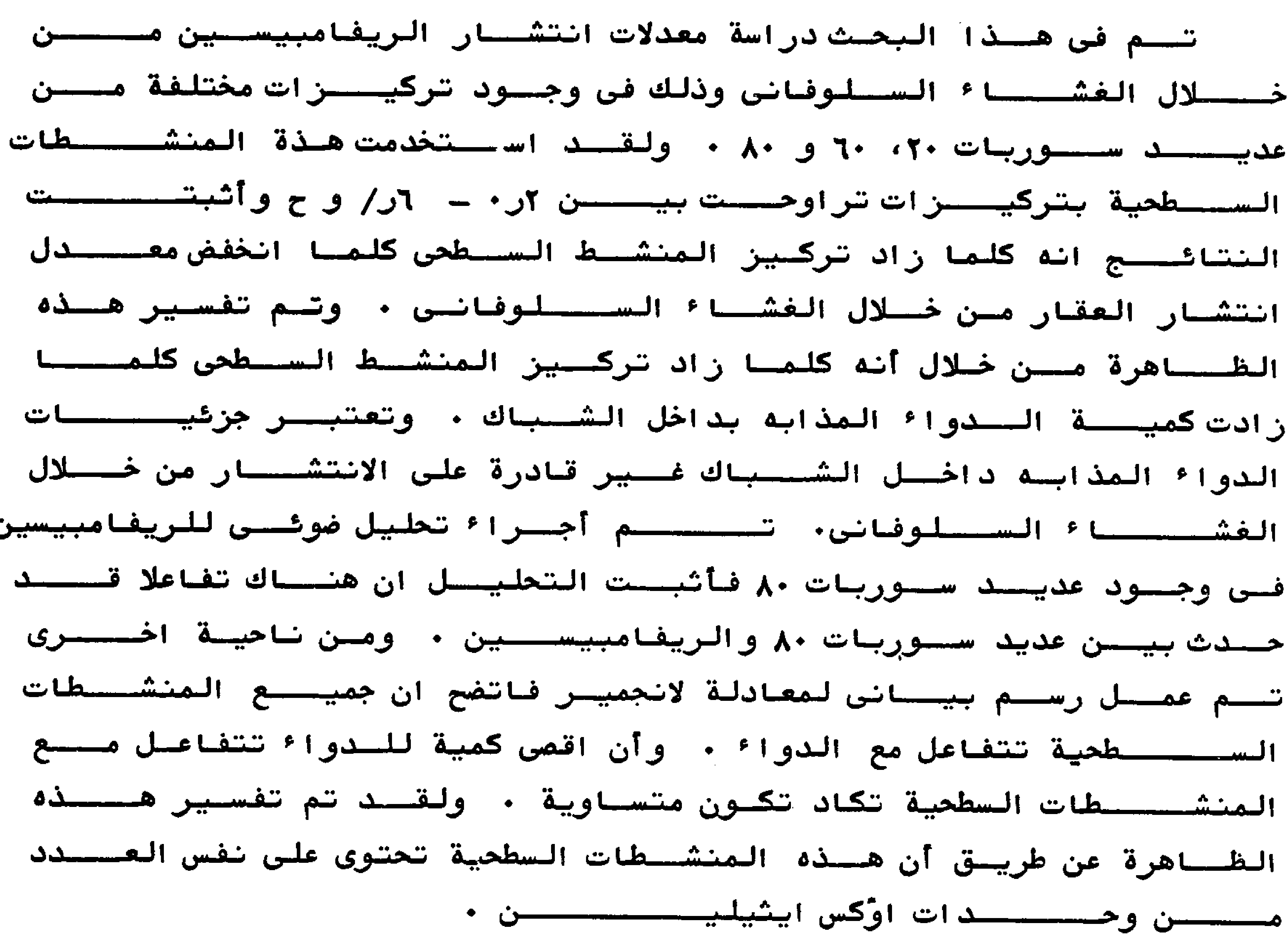

received in $4 / 10 / 1986$ \& accepted in $27 / 4 / 1987$ 